

\title{
STABILITY ANALYSIS OF COHERENT CONCENTRATION MODULATIONS
}

\author{
H. Aubauer
}

\section{To cite this version:}

H. Aubauer. STABILITY ANALYSIS OF COHERENT CONCENTRATION MODULATIONS. Journal de Physique Colloques, 1977, 38 (C7), pp.C7-385-C7-388. 10.1051/jphyscol:1977777 . jpa00217280

\section{HAL Id: jpa-00217280 \\ https://hal.science/jpa-00217280}

Submitted on 1 Jan 1977

HAL is a multi-disciplinary open access archive for the deposit and dissemination of scientific research documents, whether they are published or not. The documents may come from teaching and research institutions in France or abroad, or from public or private research centers.
L'archive ouverte pluridisciplinaire HAL, est destinée au dépôt et à la diffusion de documents scientifiques de niveau recherche, publiés ou non, émanant des établissements d'enseignement et de recherche français ou étrangers, des laboratoires publics ou privés. 


\title{
STABILITY ANALYSIS OF COHERENT CONCENTRATION MODULATIONS
}

\author{
H. P. AUBAUER
}

\author{
II. Physikalisches Institut, Universität Wien, A-1090 Wien, Austria
}

\begin{abstract}
Résumé. - La stabilité d'une structure précipitée à deux phases est analysée en respectant les changements du nombre et de la taille des domaines précipités ainsi que les variations du profil de concentration et de la largeur de la zone interfaciale, lorsqu'on maintient constante la fraction volumique du précipité.

En même temps l'énergie totale du système est évaluée à l'aide de la théorie du réseau isotrope discret. Elle peut montrer un minimum absolu pour une taille finie du précipité, si le rapport $\eta$ entre la composante de l'énergie interfaciale et la grandeur du potentiel de paire demeure au-dessous d'une certaine valeur dans le cas d'alliages en voie de mise en ordre. $\eta$ est ajusté à des diagrammes de phases réels.
\end{abstract}

\begin{abstract}
The stability of a precipitated two phase structure is analysed with respect to changes in number and size of the precipitated domains as well as to variations of the concentration profile and width of the interfacial zone, keeping the precipitate volume fraction at a constant value.

Thereby the total system energy is evaluated, using isotropic discrete lattice theory. It may show an absolute minimum at a finite precipitate size in ordering alloys, if the ratio $\eta$ out of the interfacial self energy component and of the pair potential strength stays below a certain value. $\eta$ is fitted to real phase diagrams.
\end{abstract}

1. Introduction. - Most of the equilibrium analysis was concerned so far with the stability of a homogeneous solid solution with respect to infinitesimal composition waves and with their growth [1-5]. On the other hand these theories do not enable an interpretation of numerous experiments, which hint at the existence of coherent concentration modulations in imperfectly ordered alloys, which are stable [6-10]. As a difference to the usual concept of methastability these modulations [6] form from any nearby initial state in the presence of thermal fluctuations and correspond to a minimum of total energy. Thus in contrast to the stability analysis of homogeneous alloys [1-5], the stability of already precipitated structures with respect to morphology changes is studied here, or a minimum of total energy is found, in order to enable an interpretation of these results [6-10]. As a difference to previous work [11], a microscopic or discrete lattice model is used for the interface energy density, leading to its drop with the precipitate size, corresponding to a decrease and a possible vanishing of the coarsening driving force.

2. Total Free Energy. - The total free energy of a solid solution, having the concentration $c\left(\mathbf{r}_{n}\right)$ at the lattice point $\mathbf{r}_{n}$, a homogeneous energy density $g(c)$ and a pair potential $\Omega\left(\left|\mathbf{r}_{n}-\mathbf{r}_{m}\right|\right)$, can be written as a sum over all $N$ lattice points $\mathbf{r}_{n}$ :

$$
\begin{aligned}
F & =\sum_{n}\left\{g\left[c\left(\mathbf{r}_{n}\right)\right]+f_{i}\left[c\left(\mathbf{r}_{n}\right)\right]\right\} ; \\
f_{i}(c) & =\frac{1}{2} \sum_{m}\left[c-c\left(\mathbf{r}_{m}\right)\right]^{2} \Omega\left(\left|\mathbf{r}_{n}-\mathbf{r}_{m}\right|\right) .
\end{aligned}
$$

Due to material conservation the average alloy composition $\bar{c}$ is related to the $c\left(\mathbf{r}_{n}\right)$ by

$$
\bar{c}=N^{-1} \sum_{n=1}^{N} c\left(\mathbf{r}_{n}\right)
$$

Eq. (1) is equivalent to, or can be reduced to previous results [4, 10-14].

Restricting the discussion to a monodisperse system of $M$ equally sized spherical precipitates and a special model for the free energy density :

$$
\begin{aligned}
g(c) & =\text { constant }+ \text { constant } . c+\gamma\left(1 / 4-Y^{2}\right)^{2} \\
Y & =\left[c-\left(c_{\mathrm{P}}+c_{\mathrm{M}}\right) / 2\right] / \Delta c ; \quad \Delta c=c_{\mathrm{P}}-c_{\mathrm{M}}
\end{aligned}
$$

and the pair potential

$$
\Omega(\rho)=\left\{\begin{array}{l}
0 ; \quad \rho<a \\
\Omega_{0}(v / 6-1)^{-1}\left[6(a / \rho)^{v}-v(a / \rho)^{6}\right] ; \quad \rho \geqslant a,
\end{array}\right.
$$

$F$ of eq. (1) changes its shape to :

$$
\begin{aligned}
& F=F_{\infty}+M \cdot \Sigma ; \quad F_{\infty}=N \cdot\left[Z g\left(c_{\mathrm{P}}\right)+(1-Z) g\left(c_{\mathrm{M}}\right)\right] ; \\
& Z=\left(\bar{c}-c_{\mathrm{M}}\right) / \Delta c \text {. } \\
& \Sigma=F_{0} \sum_{k=(R-D) / a}^{R / a}\left[\left(V_{k} / a^{3}\right) \eta \cdot \Delta g \cdot \gamma^{-1} \cdot \Delta c^{-4}+\right. \\
& \left.+4 \pi^{2} \sum_{t=1}^{N}\left(Y_{k}-Y_{l}\right)^{2} \cdot h(k, l)\right] \\
& F_{0}=\Omega_{0}\left(N a^{3}\right)^{2} ; \quad \eta=\gamma \cdot \Delta c^{2} /\left(\Omega_{0} \cdot N a^{3}\right) ; \\
& V_{k}=\left(4 \pi a^{3} / 3\right)\left[k^{3}-(k-1)^{3}\right] \text {; } \\
& \Delta g=\gamma \cdot \Delta c^{4}\left(1 / 4-Y_{k}^{2}\right)^{2} .
\end{aligned}
$$


$a$ denotes the lattice constant here. It is assumed, that there are $M$ precipitates of constant composition $c_{\mathbf{P}}$ and a volume fraction $Z$, which are embedded in a matrix with composition $c_{\mathrm{M}}$. $F$ is expressed here in terms of a dimensionless ratio $\eta$, that essentially represents the strength of an effective interface energy (corrected by the elastic energy) relative to the strength $\Omega_{0}$ of the interactive pair potential $\Omega$. The dimensionless geometrical energy factor $h(k, l)$ is defined by :

$$
\begin{aligned}
& h(k, l) l_{v<1}=-5 v(v / 6-1)^{-1} \times \\
& \times\left\{1 2 j ^ { - 2 } ( j ^ { 2 } - 1 ) ^ { - 2 } \left[2 j^{3}(1+2 l)+\right.\right. \\
& \left.+\left(2 l^{2}+2 l+1\right)\left(2 j^{2}-1\right)\right]+ \\
& \left.+10(k+l+1) j^{-1}\left(j^{2}-1\right)^{-1}+4 \ln \left(1-j^{-2}\right)\right\} \\
& \quad j=k-l .
\end{aligned}
$$

3. Minimization of Total Energy $F$. - The total energy $F$ is a function of the interfacial concentration profile (defined by the parameters $Y_{k}$ ), of the interface width $D$, of the precipitate radius $R$ and the ratio $\eta$. It is minimized here with respect to the $Y_{k}, D$ and $R$ as a function of the essential material constant $\eta$ with the aid of the simplex method [15]. Thereby the precipitate volume fraction $Z$ was set equal to its equilibrium value (eq. (5)), determined by the lever rule. So an increase of the precipitate size corresponds to a decrease of their number $M$. Due to limited space, the equilibrium values of the $Y_{k}$ and width $D$ are not shown here.

The total interface energy $M . \Sigma=\left(F-F_{\infty}\right)$ can be seen as the sum of a positive self energy component of interfacial volume elements (first term. within cornered brackets of eq. (5)) and an interaction term, that is negative in case of ordering (last term within cornered brackets). Considering a coarsening process at the constant volume fraction $\boldsymbol{Z}$ (decreasing precipitate number $M$ ), the first term diminishes, while the absolute value of the second one rises. This also can be seen in terms of an interface energy density, that decreases during coarsening, corresponding to a decrease of the coarsening driving force. Thus if the strength $\eta$ of the first self energy term relative to the second interaction term exceeds a critical $\eta_{\infty}$, a finite coarsening driving force exists for every finite precipitate size, causing a coarsening process, that is only limited by a lack of concentration fluctuations or the finite sample size. Thus at high temperatures unlimited coarsening appears in the case of an infinite sample volume and the precipitate size obtains an infinitly large value (figure 1).

If however the ratio $\eta$ drops below a value $\eta_{\infty}$, the driving force for coarsening vanishes at a stable precipitate size $R=R_{0}$, changing its sign for larger sizes : $R>R_{0}$. Then coarsening stops at $R=R_{0}$, even in the presence of large concentration fluctuations (figure 1). In the section 5 it is shown, that this may happen at low enough precipitate temperatures and

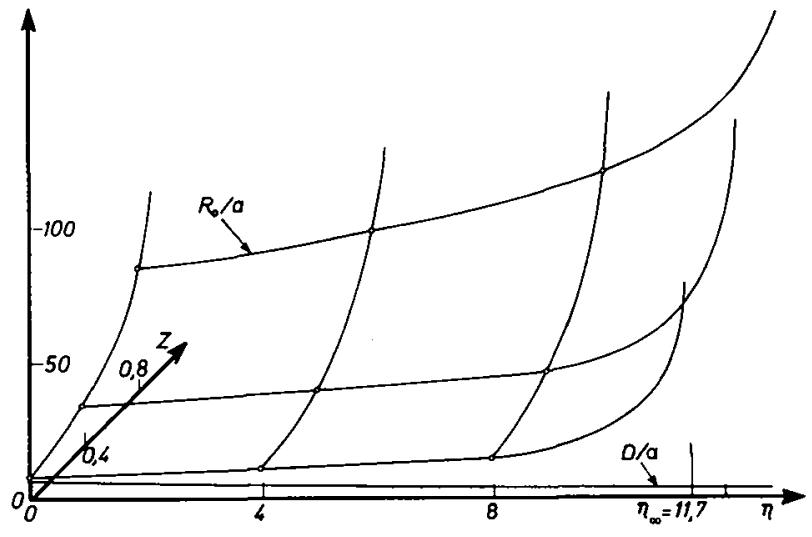

FIG. 1. - Normalized equilibrium values of the precipitate size $R_{0}$ as a function of the ratio $\eta$ and the volume fraction $Z$. For $\eta<\eta_{\infty}$ the stabilisation breaks down.

a small enough precipitate volume fraction $Z$ within phase diagrams.

Moreover the stable size $R_{0}$ increases with the precipitate volume fraction $Z$ (figure 1 ). This appears to be plausible, since it can be shown, that there exists a positive interaction energy between pairs of atoms within different precipitates. This positive precipitateprecipitate interaction partially cancels the negative one due to unequal atom pairs and it rises with the volume fraction $Z$, since this goes along with a decrease of their distance.

4. General Discussion. - During coarsening at constant fraction $Z$ the first self energy term of eq. (5) decreases due to the drop of the volume fraction of interfacial zones. The simultaneous rise of the absolute value of the second negative interaction energy term of eq. (5) is caused by an increase of the number of pairs between unequal atoms within the precipitate (concentration $c_{\mathrm{P}}$ ) and in the matrix $\left(c_{\mathrm{M}}\right)$ respectively. There are two reasons for this : Firstly the increase of the volume fraction of homogeneous material with compositions $c_{\mathrm{P}}$ and $c_{\mathrm{M}}$ respectively and secondly the drop of the interface curvature. Thus the first self energy term in eq. (5) gives a positive and the second term a negative contribution to the coarsening driving force. Thus if the ratio $\eta$ of their weight drops below a value $\eta_{\infty}$, the total coarsening-driving force may vanish.

All of this also can be discussed in the terminology of an energy density within the interfacial zone, that decreases with increasing precipitate size. If this effect outweights that of the overall decrease of interfacial area during coarsening, the latter stops.

\section{Application to Iron-Rich Fe-Al Alloy. - During} the first period of analysis quite different versions of the iron-rich side of the phase diagram were published. Even if recently general agreement as to the first order character of the transition between the $\alpha$-solid solution 
and the $\mathrm{Fe}_{3} \mathrm{Al}$ ordered phase was obtained [16], the theoretically determined two phase field $\left(\alpha+\mathrm{Fe}_{3} \mathrm{Al}\right)$ appears to extend towards lower Al-concentrations [17] $(<10$ at $\% \mathrm{Al})$, than the experimentally determined one $[18](<20$ at $\% \mathrm{Al})$ (see also figure $2 a)$. Numerous other experiments on the other hand hint at the existence of a heterogeneously ordered phase $[16,19,20]$ below 20 at $\% \mathrm{Al}$ and within the hatched area of figure $2 a$. So the left side of the hatched region was taken as a border between the disordered $\alpha$-one phase field and the $\alpha+\mathrm{Fe}_{3} \mathrm{Al}$ two phase field, as suggested earlier [19], and the excess free energy density $\Delta g$ of eq. (6) was fitted to it at two temperatures $(T=297 \mathrm{~K}$ : $c_{\mathrm{M}}=0.037, \quad c_{\mathrm{P}}=0.25 ; \quad T=813 \mathrm{~K}: c_{\mathrm{M}}=0.22$, $c_{\mathrm{P}}=0.26$ ). This way the fully drawn limits of the $\alpha+\mathrm{Fe}_{3} \mathrm{Al}$ two phase field follow. The gap closes above the eutectoid temperature $(\approx 813 \mathrm{~K})$ at $T_{\mathrm{c}}=823.5 \mathrm{~K}$. Moreover the temperature change of $\eta(T)$ can be determined. $\eta$ increases with temperature and attains its limiting value of $\eta_{\infty}$ above the eutectoid temperature (at $T=843 \mathrm{~K}$ ). Nevertheless the drop of the precipitate volume fraction $Z$ with temperature dominates the temperature dependence of the equilibrium precipitate size $R_{0}$ and their number $M_{0}$, as shown in figure $2 b$ for two alloy compositions $\bar{c}=0.106(10.6$ at $\%)$ and $\bar{c}=0.19$ (19 at $\%$ ). Thereby $R_{0}$ is found from figure 1 , using the known values of $\eta$ and $Z$, and $M_{0}$ is evaluated from this by considering material conservation of eq. (2). $R_{0}$ slightly drops with $T$, while $M_{0}$ is zero for $Z=0$ $\left(\bar{c}=c_{\mathrm{M}}\right)$ and goes through a maximum at lower temperatures. In figure $2 c$ the values of $R_{0}$ and $M_{0}$ are shown, as they change with $\bar{c}$ at a temperature $T=573 \mathrm{~K} . M_{0}$ is a factor 10 below the experimental values [19] for $0.16<\bar{c}<0.18$, while $R_{0}$ is a factor of two above it. Nevertheless, in agreement with experiment [19], a slight dependence of these values on the average composition $\bar{c}$ and no change with the ageing time arises.

A transition between the hatched two phase field, characterized by precipitate domains of a stable size and the classical two phase field $\alpha+\mathrm{Fe}_{3} \mathrm{Al}$ might be caused by a breakdown of coherency [20] due to the equilibrium radius $R_{0}$, rising with $\bar{c}$, and becoming as large as the critical radius $R_{\mathrm{c}}$. The corresponding relief of coherency strains leads to a breakdown of stabilisation. The equality of $R_{\mathrm{c}}$ with the equilibrium radius is indicated by the dotted line in figure $2 a$, agreeing qualitatively with the border between the classical two phase field $\alpha+\mathrm{Fe}_{3} \mathrm{Al}$ and the hatched anomalous region $[18,21]$ in figure $2 b$.

6. Conclusion. - A discrete lattice energy model of the interfacial zone between homogeneous precipitated regions leads to a positive self energy and a negative interaction energy contribution to the coarsening driving force. If the weight $\eta$ of the first relative to the second drops below a certain value, coarsening may stop. An application to the $\mathrm{Fe}-\mathrm{Al}$ alloy system and the $\mathrm{Cu}-\mathrm{Al}$ system (not shown here) shows a fair agreement with experiments, hinting at the existence of thermodynamically stable coherent concentration modulations in between the conventional one and two-phase zones in these alloys.

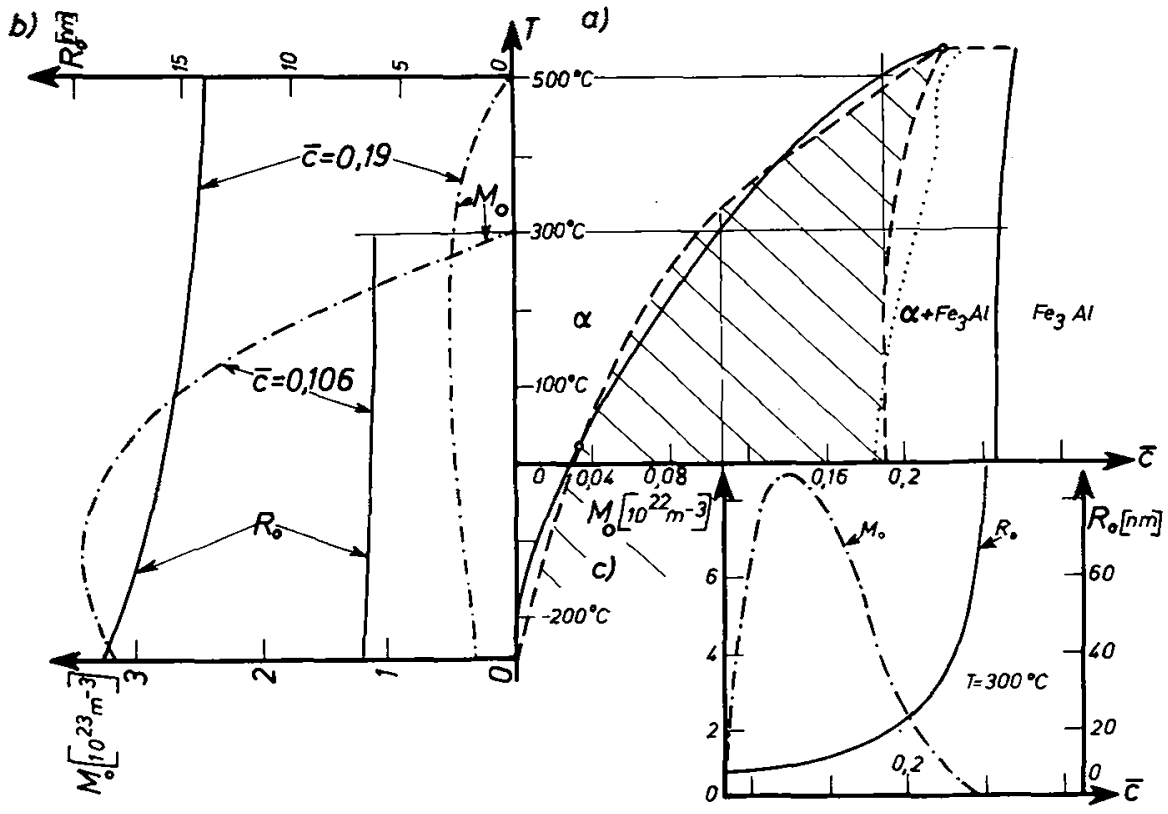

Fig. $2 a$. - The dashed lines denote the experimental and the full ones the calculated iron rich Fe-Al phase diagram. The anomalous field is hatched. $2 b$. - The temperature dependence of the equilibrium precipitate size $R_{0}$ (full lines) and their number $M_{0}$ (dashed-dotted) is shown for two alloys compositions : $\bar{c}=10.6$ at \% Al (or $\bar{c}=0.106$ ) and $\bar{c}=19$ at \% Al. $2 c,-R_{0}$ (full) and $M_{0}$ (dashed-dotted) as a function of $\bar{c}$ for $T=300^{\circ} \mathrm{C}$. 


\section{References}

[1] Hillert, M., Acta Met. 9 (1961) 525.

[2] Hilliard, J. E., Phase Transformations, Aaronson H. I. Ed., (American Society for Metals, Cleveland USA) 1968

[3] CoOK, H. E. and de Fontaine, D., Acta Met. 17 (1969) 915; ibid. 19 (1971) 607

[4] De Fontaine, D., J. Appl. Cryst. 8 (1975) 81.

De Fontaine, D., J. Phys. Chem. Solids 33 (1972) 297.

De Fontaine, D.. Acta Met. 23 (1975) 553.

[5] Langer, J. S., Bar-On, M. and Miller, H. D., Phys. Rev. A 11 (1975) 1417.

[6] Trieb, L., Siebinger, K. and Aubauer, H. P., Scripta Met. 7 (1973) 245

[7] Veith, G., Trieb, L. and Aubauer, H. P., Scripta Met. 9 (1975) 737.

[8] Warlimont, H. and Aubauer, H. P., Z. Metallkund. 64 (1973) 484

GaudiG, W. and Warlimont, H., Z. Metallkund. 60 (1969) 488.

Livshits, B. G. and Ravdel', M. P., Dokl. Akad. Nauk. SSSR 43 (1953) 1033.

[9] Das, S. K. and Thomas, G., Order Disorder Transformations in Alloys (Springer Verlag, Berlin NY) 1974

[10] Veith, G. and Tries, L.. Acta Met. 26 (1978) 185.
[11] Aubauer, H. P., Acta Met. 20 (1972) 165.

[12] Cahn, J. W. and Hilliard, J. E., J. Chem. Phys. 28 (1958) 258.

[13] Cadoret, R., Phys. Status Solidi 46 (1971) 291.

[14] De Fontaine, D. and CoOK, H. E., Critical Phenomena in Alloys Metals and Superconductors, Mills, Ascher and Jaffee Eds (McGraw-Hill) 1971.

[15] Double precision version of subroutine "MIN », based on the simplex method of CERN (Geneva, Switzerland) library. It is available from the author.

[16] Davies, R. G., J. Phys. Chem. Solids 24 (1963) 9852.

[17] Golosov, N. S., Tolstik, A. M. and Pudan, L. Ya., J. Phys. Chem. Solids 37 (1976) 273.

[18] Lutjering, G. and Warlimont, H., Acta Met. 12 (1964) 1460. WarLimont, H., Z. Metallkund. 60 (1969) 195.

SWANn, P. R., Duff, W. R. and Fischer, R. M., Met. Trans. 3 (1972) 409.

OKamoto, H. and BeCK, P. A., Met. Trans. 2 (1971) 569.

[19] Warlimont, H. and Thomas, G., Metal. Sci. J. 4 (1970) 47.

[20] Saito, H. and Morita, H., J. Japan Inst. Met. 30 (1966) 930.

[21] BRooks, H., Metal Interfaces (American Society for Metals, Cleveland USA) 1952. 